\title{
Biochemical investigation of histidinaemia
}

\author{
J. B. HOLTON, F. J. W. LEWIS, AND G. R. MOORE
}

From the Department of Pathology, Southmead Hospital, Bristol

SYNOPSIS A 6-month-old child with a history of recurrent infections, convulsions, and retarded development had biochemical findings which were typical of histidinaemia. The enzyme histidase has been shown to be absent from the skin of the patient. The results of histidine-loading experiments in the parents of the child suggest that they may both metabolise this amino-acid abnormally. A simple method of estimating histidine in plasma and urine is described.

In 1961 Ghadimi, Partington, and Hunter described an inherited disorder of histidine metabolism. They found two sisters who had histidinaemia, with an increased excretion of histidine and other imidazole compounds. Similar abnormalities have now been described in four other children (Auerbach, DiGeorge, Baldridge, Tourtellotte, and Brigham, 1962; $\mathrm{La} \mathrm{Du}$, Howell, Jacoby, Seegmiller, Sober, Zannoni, Canby, and Ziegler, 1963; Davies and Robinson, 1963). In all cases the biochemical findings suggested that the metabolic defect resulted from a lack of histidase, the enzyme which converts histidine to urocanic acid (Fig. 1).

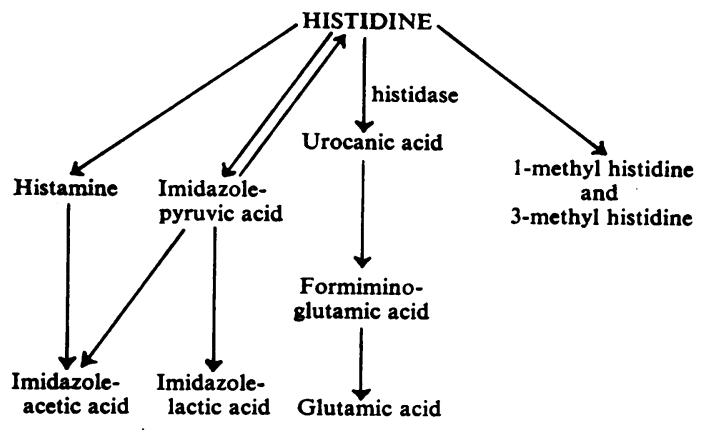

FIG. 1. Diagram showing the metabolism of histidine.

There have been no consistent clinical findings associated with the disorder. One child with histidinaemia was quite normal and four cases had only a slight speech defect. However, a more serious condition was found in the 5-year-old boy studied by Davies and Robinson (1963). In this patient, frequent infections were sometimes accompanied by convulsions, and the child was both mentally and physically retarded.

Received for publication 6 March 1964.
The urine of patients with histidinaemia usually give a positive result in the Phenistix test and a green colour with ferric chloride solution. In most cases, this finding prompted the full biochemical investigation leading to the diagnosis. The object of the present paper is to describe the methods and results of studying a 6-month-old boy with histidinaemia, who was admitted to hospital because of recurrent infections, convulsions, and retarded development. ${ }^{1}$ Oral histidine loading tests on both parents suggest that they, also, metabolise the amino-acid abnormally.

\section{METHODS}

URINE Urine was examined by the routine tests for phenylketonuria with Phenistix (Ames Company) and $10 \%$ ferric chloride. Before two-dimensional chromatography the urine was desalted using Zeokarb 225 (Smith, 1958a). Chromatograms were run in two different solvent systems: (1) butanol, acetic acid, water followed by butanol, pyridine, water, and (2) butanol, acetic acid, water followed by phenol, ammonia. The chromatograms were stained for amino-acids with ninhydrin and for imidazole compounds with Pauly's and p-anisidine reagents. The preparation of solvents and staining reagents was carried out as described by Smith (1958b).

Histidine was estimated by applying $5 \mu \mathrm{l}$. of urine, or a suitable dilution, along a $1 \mathrm{~cm}$. wide line on paper electrophoresis strips $(5 \times 25 \mathrm{~cm}$., Whatman no. 1$)$. Electrophoresis was carried out in acetic acid/pyridine buffer $p H 5.4$ (Kohn, Mollin, and Rosenbach, 1961), at $300 \mathrm{~V}$., for 15 minutes. At the end of the run the strips were stained with Pauly's reagent. Under these conditions histidine migrated about $2 \mathrm{~cm}$. from the origin towards the cathode. In normal urines, histidine was the only compound which stained with Pauly's reagent. Urines from the patient had an additional spot on the origin which was due to imidazole-lactic and -pyruvic acids. The histidine spot in each strip was compared visually with those given by $5 \mu$ l. of solutions of known histidine ${ }^{1}$ The full clinical details of this case will be published elsewhere. 
concentration. The urine histidine concentration was assessed to the nearest $25 \mu \mathrm{g} . / \mathrm{ml}$. over the range 50 to $300 \mu \mathrm{g} . / \mathrm{ml}$.

Formiminoglutamic acid (FIGLU) was detected in urine by the method of Lewis and Moore (1962). In this technique any glutamic acid present is first destroyed with chloramine $T$. The urine product is then desalted with Zeokarb 225, and on eluting with ammonia, the FIGLU present is converted to glutamic acid. The eluate is concentrated, up to 100 times if necessary, until the glutamic acid can be detected after electrophoresis and staining with ninhydrin. The degree of concentration required, which may be expressed in terms of the creatinine level of the concentrated eluate, gives a semiquantitative measure of the FIGLU present.

PLASMA Histidine was estimated in heparinized plasma by visual comparison of spots obtained on electrophoresis of protein-free extracts of plasma by a similar technique to that of urine. The amino-acids were extracted by the method of Giri, Krishnamurthy, and Venkitasubramanian (1952). Plasma (1 ml.) was mixed with ethanol $(3 \mathrm{ml}$.$) , centrifuged, and the supernatant$ equilibrated with chloroform (12 ml.). After centrifuging, the upper aqueous phase contains the aminoacids and $5 \mu \mathrm{l}$. of this extract was used for electrophoresis. The method was calibrated with plasma containing a standard amount of histidine, which was extracted and treated as above.

HISTIDINE LOADING TEST In children, water $(2 \mathrm{ml} / \mathrm{kg}$. body weight) was given every half hour, from one hour before to three hours after taking histidine. Histidine (100 mg./kg.) was given dissolved in orange juice. All urines passed, from one hour before to six hours after the histidine, were collected separately.

In adults, $150 \mathrm{ml}$. of water was drunk every half hour, from one hour before the histidine load (15g.) to eight hours after. Blood samples were taken at zero time, one, three, and four hours after histidine. Urines were collected for two-hour periods after giving histidine, up to eight hours.

UROCANIC ACID LOADING TEST A solution of urocanic acid for intravenous injection was prepared by the method of Auerbach et al. (1962). Urocanic acid dihydrate $(340 \mathrm{mg}$.) was administered to the patient and all urines were collected for the next 24 hours.

SKIN HISTIDASE ASSAY Histidase activity was determined in homogenates of stratum corneum by the technique of Zannoni and $\mathrm{La} \mathrm{Du}(1963)$. Samples were obtained from the cornified skin adjacent to the finger nails.

\section{RESULTS}

URINE The urine of the patient usually gave a positive Phenistix and a green colour with ferric chloride. Positive Phenistix and ferric chloride tests were found, after histidine loading, in the father of the patient. However, one of the group of control

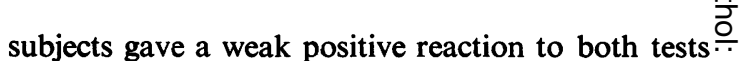
after taking histidine. The colour with ferric chloride $\overrightarrow{\vec{F}}$ developed very slowly, taking about 10 minutes toreach a maximum. In contrast, urines from phenylketonuric patients give an immediate green colour $\frac{\bar{\sigma}}{\frac{5}{1}}$ with ferric chloride.

A two-way chromatogram on a random urine $\stackrel{\mathbb{D}}{\curvearrowright}$ sample from the patient, stained with ninhydrin, showed a predominant spot of histidine. The $\overrightarrow{0}$ average 24-hour excretion of histidine of the patient $\vec{\overrightarrow{ }}$ was $218 \mathrm{mg}$. with a concentration of $150 \mathrm{mg} . / 100 \mathrm{ml}$. The normal values found by Ghadimi et al. (1962) for 13 children, aged 3 to 13 years, were from? 10 to $160 \mathrm{mg}$. $/ 24$ hours (concentration range $3 \cdot 1 \vec{V}$ to $26.6 \mathrm{mg}$./100 ml.). No figures were available for children as young as our patient. Two normal $\stackrel{?}{y}$ children, aged 6 and 15 months, both gave 24-hour excretions of $28 \mathrm{mg}$. by our method.

The 24-hour excretion of histidine in the mother $\vec{z}$ and father of the patient was $150 \mathrm{mg}$. and $273 \mathrm{mg}$. O respectively (normal range 110 to $320 \mathrm{mg}$., Harris, 1957).

The urine chromatograms of the patient showed a $\stackrel{\Phi}{-}$ large spot of histidine and increases in other imida- $\vec{\bullet}$ zole compounds compared with the normal (Fig. 2). Two of these compounds were identified as imidazole-acetic acid and imidazole-lactic acid and one other unidentified, Pauly-staining compound was present in the patient's urine.

PLASMA The average histidine level found in the patient was $14 \mathrm{mg}$. $/ 100 \mathrm{ml}$. The values found in two normals, of the same age and sex as the patient, were less than $3 \mathrm{mg}$./100 ml. by our method. The mean normal for children, found by Ghadimi $e t$ al. (1962), was $1 \mathrm{mg} . / 100 \mathrm{ml}$. A normal fasting histidine value was found in the mother of the patient, but the father's histidine level $(3 \mathrm{mg} . / 100 \mathrm{ml}$.) appeared to be slightly higher than normal.

HISTIDINE LOADING TEST After a histidine load of 0 $100 \mathrm{mg} . / \mathrm{kg}$. body weight the patient excreted $21 \mathrm{mg}$. in three hours or $5.3 \mathrm{mg}$. $/ \mathrm{kg}$. body weight. After an equivalent dose of histidine a child control excreted $3.1 \mathrm{mg}$. in three hours, or $0.2 \mathrm{mg}$. $/ \mathrm{kg}$.

Two-way chromatograms of urines collected four hours after a histidine load showed a striking difference between the patient and a normal, when stained to detect imidazole compounds (Fig. 3).

After a histidine load no urocanic acid could be $\stackrel{\circ}{\square}$ found in the urine of the patient by chromatography. FIGLU could only just be detected after the urine had been concentrated a hundred times (to a creatinine concentration of $80 \mathrm{~g}$./l.). In the normal adult $\stackrel{\mathbb{D}}{\overparen{D}}$ FIGLU could sometimes be detected in the urine $\frac{?}{\mathbb{D}}$ before concentration and always after a two- to 

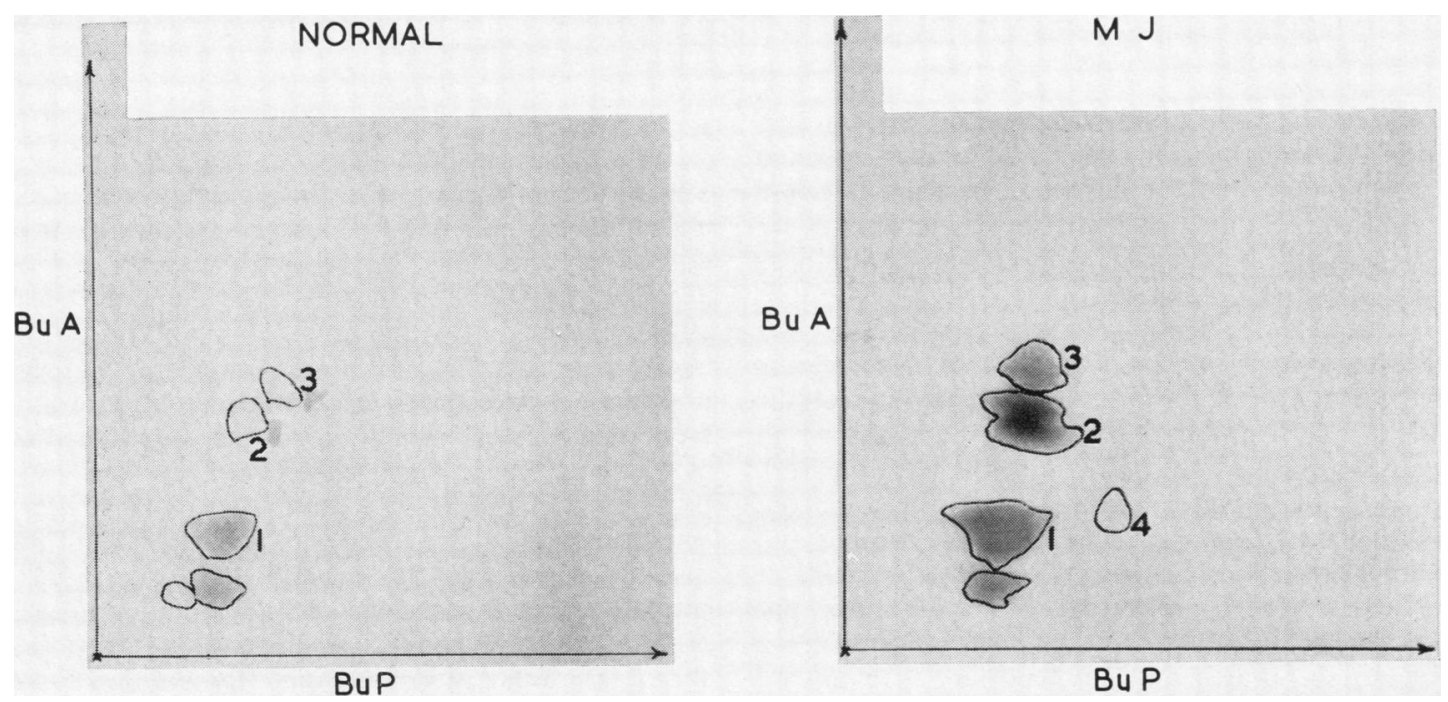

FIG. 2. Two-way chromatograms of the urine of the patient and a normal adult: $50 \mu l$. of desalted urine was applied to each chromatogram and the solvents were butanol/pyridine water $(B u P)$ and butanol/acetic acid/water (BuA). The chromatograms were stained with Pauly's reagent.

Key to compounds: 1 double spot of histidine; 2 imidazole lactic acid; 3 imidazole acetic acid; 4 unidentified compound.
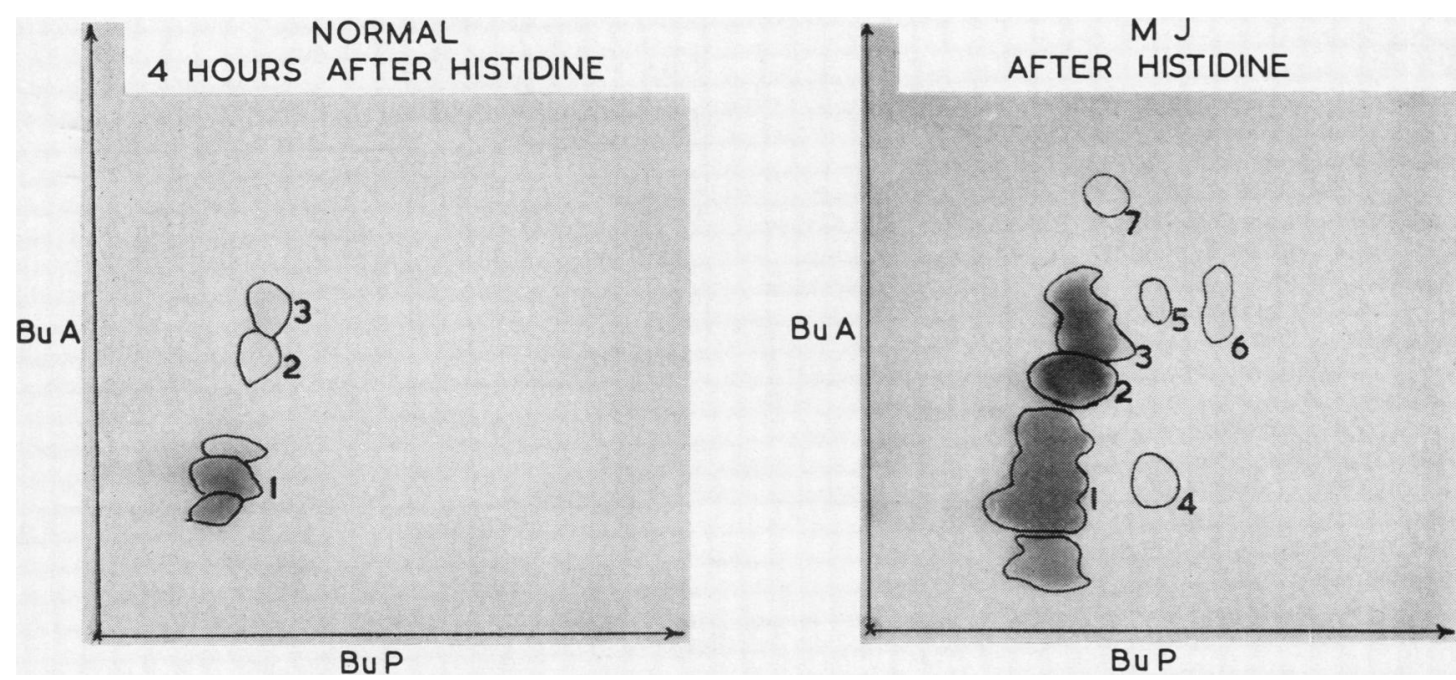

FIG. 3. Two-way chromatograms of the urine of the patient and a normal adult four hours after an oral histidine load. Experimental details are the same as those for Figure 2.

Key to compounds: 1, 2, and 3, as in Fig. 2; 4, 5, 6, 7, unidentified compounds. 
five-fold concentration (at a creatinine level of 1 to $2 \cdot 5 \mathrm{~g}$./1.).

UROCANIC ACID LOADING TEST After the intravenous injection of urocanic acid, the patient excreted a large amount of this compound. In urine collected three to six hours after the urocanic acid load, FIGLU could be detected without any preliminary concentration of the urine.

HISTIDINE LOADING TEST ON ADULTS The results of the histidine loading test in the parents of the patient and eight control subjects are shown in Figures 4 and 5. The control subjects were medical, nursing, and laboratory staff (five male, three female).

The plasma levels of histidine in the mother and father were above the range shown by controls at the second, third, and fourth hours after the oral load (Fig. 4). Both parents excreted more histidine between the fourth and eighth hours than any of the controls did in this period (Fig. 5).

SKIN HISTIDASE ASSAY Six control adults had skin histidase activities within the range found by Zannoni and $\mathrm{La} \mathrm{Du}(1963)$, viz., $1 \cdot 8$ to $5 \cdot 3 \mu$ moles urocanic acid formed $/ \mathrm{hr}$./g. fresh tissue. In the patient no urocanic acid was present in the skin initially, and the formation of urocanic acid could not be detected on incubation. According to Zannoni and $\mathrm{La} \mathrm{Du}$,

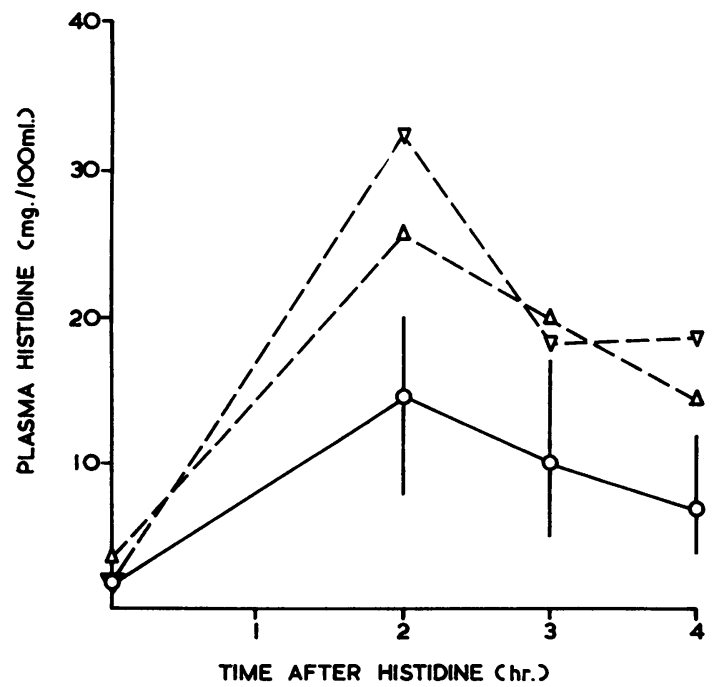

FIG. 4. Plasma levels of histidine after a $15 \mathrm{~g}$. load given orally.

$\bigcirc-O$ Mean of eight controls. The thin vertical lines show the range of the control values.

$\triangle----\triangle \quad$ Father of the patient.

$\nabla--\ldots-\nabla \quad$ Mother of the patient. normal children have higher levels of skin histidase than adults (4.2-6.6 units).

DISCUSSION

The number of cases of histidinaemia reported in the literature is small but it does not follow that the disease is rare. The majority of patients so far described have presented only with a speech defect after an apparently uneventful infancy; it is unlikely, therefore, that such children will have had any biochemical investigations. If the condition is, in fact, being missed, awareness of this should lead to many more cases being discovered, as has been happening in the United States ( $\mathrm{La} \mathrm{Du}$, personal communication). The severity of this case and of the case described by Davies and Robinson (1963) emphasizes the importance of following up doubtful or intermittently positive Phenistix tests with full chromatographic investigations. By analogy with phenylketonuria, and some other metabolic diseases, treatment with a reduced histidine intake may prove successful. In this connexion a food of low histidine content is now available commercially. ${ }^{2}$

The methods described here for the estimation of histidine in plasma and urine are quite adequate for the investigation of histidinaemia since, in all cases reported, values of these have been four or five times 'Scientific Hospital Supplies Ltd., Liverpool.

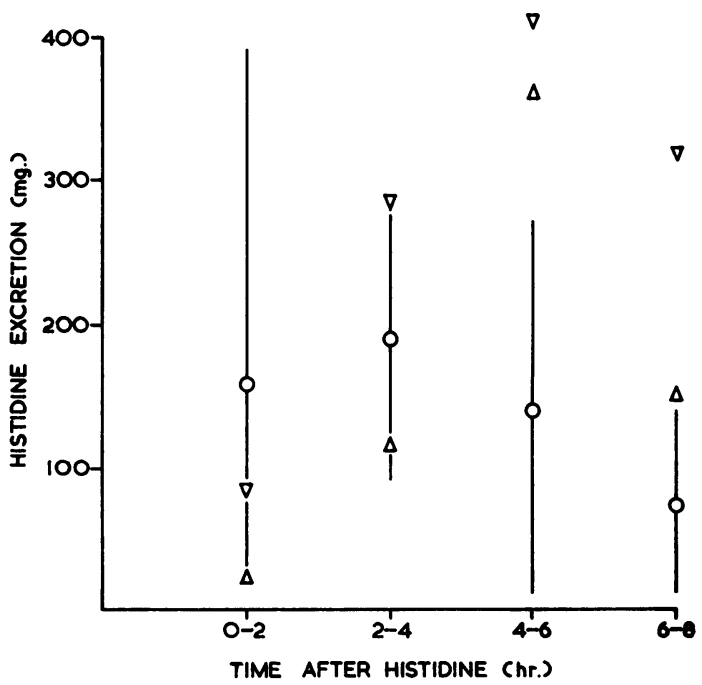

FIG. 5. Urinary excretion of histidine after a $15 \mathrm{~g}$. load given orally.

Mean of eight controls. The thin vertical lines show the range of the control values.

$\triangle$ Father of the patient.

$\nabla \quad$ Mother of the patient. 
the normal range. In our eight normal adults the plasma histidine was always less than the $3 \mathrm{mg}$./ $100 \mathrm{ml}$. standard. This compares with a range of 0.8 to $3.8 \mathrm{mg} . / 100 \mathrm{ml}$. by the Moore and Stein technique (Westall, 1962) and 0.1 to $2.6 \mathrm{mg}$. $/ 100 \mathrm{ml}$. by the L-amino-acid oxidase method (Baldridge and Greenberg, 1963). The method can be introduced rapidly in any laboratory with facilities for electrophoresis. For more accurate purposes, especially in controlling dietary treatment, the Moore and Stein or L-amino-acid oxidase techniques would be preferable. The latter is a modification of a method for phenylalanine (La Du and Michael, 1960) which many laboratories are now using.

The results in the case described here are similar to those in other children with histidinaemia, and they are consistent with the patient having a block in the conversion of histidine to urocanic acid. An assay of histidase has been made on the skin of the patient and there was no enzyme activity. The direct demonstration of the enzyme block has been reported previously in two cases (La Du et al., 1963). The failure to break down histidine by the main pathway produces large increases in other metabolites, notably imidazole-lactic acid and imidazole-acetic acid, which are formed via imidazole-pyruvic acid and histamine (Fig. 1).

Imidazole-pyruvic acid is thought to be responsible for the positive Phenistix and ferric chloride tests in histidinaemia (La Du et al., 1963), and so it is probable that this compound was also excreted in our case.

There seems little doubt that histidinaemia is an inborn error of metabolism. Two families have now been described with more than one sibling with the disease (Ghadimi et al., 1962; La Du et al., 1963), and the biochemical disorder appears to be the result of a single enzyme defect. Previous studies on the parents of the children with histidinaemia have produced little evidence for any biochemical abnormality in the parents. The results reported here, on the effects of an oral load of histidine, suggest that both the mother and father of the patient metabolized this amino-acid abnormally. It is probable, therefore, that both parents are heterozygous for the condition.

We would like to thank Dr. Beryl Corner for permission to publish this paper, and her staff at Southmead Hospital for their cooperation. We acknowledge the Ethel Showering fund for defraying some of the expenses.

\section{REFERENCES}

Auerbach, V. H., DiGeorge, A. M., Baldridge, R. C., Tourtellotte, C. D., and Brigham, M. P. (1962). J. Pediat., 60, 487.

Baldridge, R. C., and Greenberg, N. (1963). J. Lab. clin. Med., 61, 700.

Davies, H. E., and Robinson, M. J. (1963). Arch. Dis. Childh., 38, 80.

Ghadimi, H., Partington, M. W., and Hunter, A. (1961). New Engl. J. Med., 265, 221.

,,---1962 ). Pediatrics, 29, 714.

Giri, K. V., Krishnamurthy, K., and Venkitasubramanian, T. A. (1952). Lancet, 2, 562.

Harris, H. (1957). In Biochemical Disorders in Human Disease, edited by R. H. S. Thompson, and E. J. King, p. 579. Churchill, London.

Kohn, J., Mollin, D. L., and Rosenbach, L. M. (1961). J. clin. Path., $14,345$.

La Du, B. N., Howell, R. R., Jacoby, G. A., Seegmiller, J. E., Sober, E. K., Zannoni, V. G., Canby, J. P., and Ziegler, L. K. (1963). Pediatrics, 32, 216.

- and Michael, P. J. (1960). J. Lab. clin. Med., 55, 491.

Lewis, F. J. W., and Moore, G. R. (1962). Lancet, 2, 359.

Smith, I. (1958a). Chromatographic Techniques, p. 50. Heinemann, London.

(1958b). Ibid., p. 141. Heizemann, London.

Westall, R. G. (1962). In Amino-acid Pools, edited by J. T. Holden, p. 198. Elsevier, Amsterdam.

Zannoni, V. G., and La Du, B. N. (1963). Biochem. J., 88, 160. 